\section{Commentary: Pulmonary valve bioprosthesis: Longevity and reintervention}

\author{
Harold M. Burkhart, MD, ${ }^{a}$ and \\ Sabrina D. Phillips, MD ${ }^{b}$
}

Despite advances in surgical techniques, residual pulmonary valve regurgitation and right ventricular outflow tract obstruction remain problematic for many patients with tetralogy of Fallot, pulmonary atresia with ventricular septal defect, and congenital pulmonary valve stenosis after their initial surgical intervention. ${ }^{1}$ Pulmonary valve regurgitation has been especially detrimental to these patients' long-term cardiovascular health, as morbidity related to chronic pulmonary valve regurgitation was not initially recognized, pulmonary valve regurgitation diagnosis can be missed by providers who do not care for congenital heart disease patients regularly, and appropriate intervention strategies to treat pulmonary valve regurgitation are uncertain and evolving. Bioprosthetic valves have been favored at the time of surgical intervention for the pulmonary valve to reduce anticoagulation requirements, and transcatheter valves are obligate bioprostheses. The predominant concern regarding pulmonary valve replacement/implantation is the longevity of the bioprosthesis., ${ }^{2,3}$

In this issue of the Journal, Baird and colleagues ${ }^{4}$ present a multi-institutional, retrospective review of 1278 patients younger than the age of 30 years who underwent surgical pulmonary valve replacement (PVR). Mean age at PVR was 19 years with a median follow-up of 3.9 years. This paper represents a large cohort of patients and provides valuable data regarding bioprosthetic valve senescence

From the ${ }^{\mathrm{a} D i v i s i o n}$ of Cardiovascular and Thoracic Surgery, University of Oklahoma Health Sciences Center, Oklahoma City, Okla; and ${ }^{\mathrm{b}}$ Department of Cardiology, Mayo Clinic, Jacksonville, Fla.

Disclosures: The authors reported no conflicts of interest.

The Journal policy requires editors and reviewers to disclose conflicts of interest and to decline handling or reviewing manuscripts for which they may have a conflict of interest. The editors and reviewers of this article have no conflicts of interest.

Received for publication Aug 2, 2020; revisions received Aug 2, 2020; accepted for publication Aug 3, 2020; available ahead of print Aug 5, 2020.

Address for reprints: Harold M. Burkhart, MD, Division of Cardiovascular and Thoracic Surgery, University of Oklahoma Health Sciences Center, P.O. Box 26901, WP-2230, Oklahoma City, OK 73105 (E-mail: Harold-burkhart@ouhsc. edu).

J Thorac Cardiovasc Surg 2021;161:364-5

0022-5223/\$36.00

Copyright (c) 2020 by The American Association for Thoracic Surgery

https://doi.org/10.1016/j.jtcvs.2020.08.003

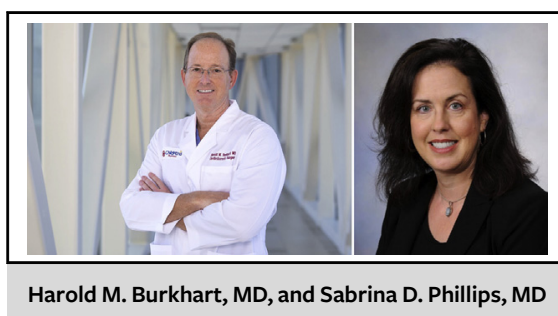

CENTRAL MESSAGE

Patients requiring a bio-

prosthetic pulmonary valve will

need multiple valve interventions

in their lifetime. Valve longevity, in

addition to time to reinterven-

tion, must play a role when

deciding valve strategies.

and the risk factors for reintervention. The overall reintervention rate was $12.7 \%$ with, perhaps not surprisingly, the majority $(85.2 \%)$ occurring in the children. Importantly, they found that patients over the age of 18 years had a median time to reintervention of 17.7 years, affirming what most adult congenital heart disease practitioners have noted clinically and refuting the common concern that bioprosthetic valves in any cardiac position have an average life span of 10 years. In addition, they point out that certain valves, independent of patient age and valve size, perform worse than other valve types. Finally, on univariate analysis, anticoagulation seemed to be advantageous with regard to time to reintervention.

The authors are fairly thorough in their discussion of the limitations of this study, including differences in surgical technique as well as variances in institutional timing for reintervention. Including data on the timeline for prosthetic valve dysfunction would have strengthened the manuscript. When deciding on the best bioprosthetic valve to use for PVR, knowing how long the valve functions properly is likely just as important as time to reintervention. We are all aware that even in the face of a dysfunctional pulmonary valve bioprosthesis, timing for another surgical intervention may be deferred for a number of reasons in an effort to put off the inevitable next procedure. Egbe and colleagues ${ }^{5}$ recently published a review of 807 bioprosthetic pulmonary valves in 573 adult patients, looking at time to pulmonary prosthesis valve dysfunction. They reported a time to valve dysfunction of 12.6 years with a cumulative incidence of 
$27 \%$ and $48 \%$ at 10 and 15 years, respectively. If the median time to reintervention was 17.7 years in the current study, one has to wonder whether reintervention in some patients may have been delayed and if they would have benefited with earlier reintervention.

In conclusion, the authors present a large retrospective review of pulmonary bioprosthesis in children and young adults. They confirm that younger patients, smaller valves, and certain valve types are at risk of earlier reintervention. Although adult patients fared better with regard to reintervention, given the young age at time of intervention for these adult patients, even a median time of 17.7 years to intervention necessitates that patients will need potentially multiple valve procedures in their lifetime. This underscores the importance of evaluation strategies, including bioprosthetic valve dysfunction, for patients with pulmonary valve disease to delineate the most appropriate valve and time for surgical or transcatheter intervention.

\section{References}

1. Sabate Rotes A, Eidem BW, Connolly HM, Bonnichsen CR, Rosedahl JK, Schaff HV, et al. Long-term follow-up after pulmonary valve replacement in repaired tetralogy of Fallot. Am J Cardiol. 2014;114:901-8.

2. Kwak JG, Bang JH, Cho S, Kim ER, Shih BC-H, Lee C-H, et al. Long-term durability of bioprosthetic valves in pulmonary position: pericardial versus porcine valves. J Thorac Cardiovasc Surg. 2020;160:476-84.

3. Shinkawa T, Lu CK, Chipman C, Tang X, Gossett JM, Imamura M. The midterm outcomes of bioprosthetic pulmonary valve replacement in children. Semin Thorac Surg. 2015;27:310-8

4. Baird CW, Chavez M, Sleeper LA, Borisuk MJ, Bacha EA, Burchill L, et al Reintervention rates after bioprosthetic pulmonary valve replacement in patients younger than 30 years of age: a multicenter analysis. J Thorac Cardiovasc Surg. 2021; 161:345-62.e2.

5. Egbe AC, Connolloy HM, Miranda WR, Dearani JA, Schaff HV. Outcomes of bioprosthetic valves in the pulmonary position in adults with congenital heart disease. Ann Thorac Surg. 2019;108:1410-5.
See Article page 345 .

\section{Commentary: In pursuit of the perfect pulmonary valve....}

\author{
John D. Cleveland, MD, and \\ S. Ram Kumar, MD, PhD, FACS
}

Improved surgical outcomes for congenital heart disease have resulted in a population of patients with residual cardiac lesions that must be addressed later in life. The most common is right ventricular outflow tract (RVOT) stenosis or regurgitation that necessitates RVOT reconstruction, usually requiring implantation or replacement of the pulmonary valve (PVR). In an ideal world, the perfect pulmonary valve would be implanted via a minimally invasive

\footnotetext{
From the Division of Cardiac Surgery, Department of Surgery, Keck School of Medicine of the University of Southern California; and Heart Institute, Children's Hospital Los Angeles, Los Angeles, Calif.

Disclosures: The authors reported no conflicts of interest.

The Journal policy requires editors and reviewers to disclose conflicts of interest and to decline handling or reviewing manuscripts for which they may have a conflict of interest. The editors and reviewers of this article have no conflicts of interest.

Received for publication Aug 12, 2020; revisions received Aug 12, 2020; accepted for publication Aug 13, 2020; available ahead of print Aug 15, 2020

Address for reprints: S. Ram Kumar, MD, PhD, FACS, Children's Hospital Los Angeles, 4650 Sunset Blvd, Mailstop \#66, Los Angeles, CA 90027 (E-mail: rsubramanyan@surgery.usc.edu).

J Thorac Cardiovasc Surg 2021;161:365-7

0022-5223/\$36.00

Copyright (c) 2020 by The American Association for Thoracic Surgery

https://doi.org/10.1016/j.jtcvs.2020.08.036
} 